\title{
Creativity: Linking Theory and Practice for Entrepreneurs Tom Duxbury
}

\author{
(Creativity represents a balance between knowledge and freeing" \\ oneself of that knowledge. \\ Robert J. Sternberg \\ Psychologist and author
}

\begin{abstract}
In this article, creativity research is brought into focus for those involved in the practice of entrepreneurship. The author provides a background on creativity research, how it is defined, and systems models that attempt to explain it. The author distinguishes between creative and innovative activities, and provides advice to entrepreneurs to help realize the creative potential of their organizations. The author reinforces the view that entrepreneurs create new value by investing in ideas, and specific recommendations are made for creating supportive structures, building teams of creative individuals, and successfully championing ideas to acquire the resources they need to produce innovations.
\end{abstract}

\section{Introduction}

Creativity, in the form of the ability to effectively generate novel solutions to relevant problems, can be a source of significant competitive advantage, especially in rapidly changing environments. Creativity is important to entrepreneurs because it is the first stage in the process of innovation, providing the stimulus for opportunity discovery and new venture creation. As new entrants, entrepreneurs often justify themselves upon the same dimensions as creativity: novelty, usefulness, and appropriateness. Arguably, one of the first tasks demanded of an entrepreneur is to manifest creative ability through the conceiving of new product-market opportunities and unique value propositions. From these initial acts of creativity, entrepreneurs must build effective organizations that can repeatedly bring ideas to commercially valuable forms in order to survive and grow.

This article begins with a brief review of perspectives on creativity in organizations and examines the interaction of personal attributes and the work context. The relationship with innovation is distinguished next, with a view towards aligning appropriate activities with stage of development. In organizational contexts, creativity does not occur in isolation, and systems models that attempt to explain interaction effects are highlighted. The article concludes with specific recommendations to entrepreneurs in setting the creative climate internally and selling their ideas externally.

This article is targeted towards entrepreneurs seeking actionable knowledge from creativity research. Firstly, it is useful to begin with a clarification of what the creativity construct represents in modern usage.

\section{What is Creativity?}

Creativity has evolved from origins in mysticism and divine inspiration to being a key performance contributor in helping organizations adapt to changing environments. There have been many conceptualizations of creativity over time, but research over the past fifty years has produced some consistent themes. It has been defined variously as a process, as a product outcome, and in social constructionist terms. Creativity is most commonly described today as the generation or production of ideas that are novel and useful (Amabile, 1988; Res. in Org. Behavior, Vol. 10: 123-167). In order to be useful, creative ideas must also be appropriate, that is, of potential value towards accomplishing desired goals. These ideas may reflect either a recombination of existing materials or an introduction of new materials to the organization (James and Drown, 2012; tinyurl.com/ cx74bfx). Selection among alternatives is important; the 


\section{Creativity: Linking Theory and Practice for Entrepreneurs}

Tom Duxbury

task to be completed "must be open ended, rather than having a single, obvious solution" (Amabile and Mueller, 2008; tinyurl.com/clfh925). Although various qualifiers have been attached to creative activity, it remains central to the innovative capacity of modern organizations.

The main conceptual challenge with creativity as ideas that are novel, useful, and appropriate, is that it is difficult to objectively measure as an output variable, as it depends upon the context and observer's perspective. Following this viewpoint, Ford (1996; tinyurl.com/bmfj7w7) argues that creativity is a "domain-specific, subjective judgment of the novelty and value of an outcome of a particular action". The domain is a cultural aspect that includes the structured knowledge system that an individual must access and gain knowledge of, in order to create something new and make a change to the domain. The criteria of novelty, usefulness, and value towards goals raise the question of $w h o$ is to make that decision. Csikszentmihalyi (1999; tinyurl.com/bonozgt) argues that it is the experts within a domain who are the gatekeepers of such value judgments; they constitute "the field" and define what is creative. In practice, gatekeepers of domains may extend well beyond the experts, to include anyone with influence within that domain (Ford, 1996; tinyurl.com/bmfj7w7). In new product development for example, the field may include fellow developers, the CTO, an entrepreneur-leader, lead users, analysts, and investors.

In Csikszentmihalyi's systems model, domains interact with fields and individual behaviours to produce something that is potentially creative; only when a lasting change to a domain has been made, can it be said that creativity occurred. The concept of lasting domain change as a test of creativity has the appeal of objectivity, however it also means that creativity may only be established after the fact. Thus, timing is also an important consideration in determining creativity. For instance, when Apple's iPhone first appeared, critics initially panned the device as lacking novelty, demonstrating "nothing new". However, few would argue that over time, the iPhone has made a lasting change to the domain of smartphones, and thus became creative. Two consequences of creative domain change for entrepreneurs are that: i) it will likely be initially challenged by those representing the skeptical field and ii) creativity takes time and persistence to prove out.

In organizational contexts specifically, Mumford, Hester, and Robledo (2012; tinyurl.com/cx74bfx) assert that creativity is the "production of high-quality, original, and elegant solutions to problems". Their definition emphasizes the performance nature of creativity and further implies that it is a problem-solving activity involving cognition at high levels, from which decisions will be made. This view underscores the deliberate undertaking of creativity as a means for generating better solutions, rather than a "flash out of the blue". The conditions of novelty, usefulness, and appropriateness remain valuable criteria in helping distinguish creativity from other organizational routines. Wild ideas for example, while novel, are not viewed as creative unless (or until) they are useful to an organization. As George (2007; tinyurl.com/d2xbobk) put it:

"Novelty for novelty's sake, therefore is not the same thing as creativity. Similarly, effective problem solving is certainly useful in organizations but does not necessarily reflect creativity; in order for problem solving to be creative, generated solutions must be novel."

Creativity can be considered to exist along a continuum, with activities ranging from incremental (minor adaptations) to radical (major breakthroughs). In considering the type of problems requiring creative thought, Mumford, Hester, and Robledo (2012; tinyurl.com/cx74bfx) list five problem characteristics; they are: i) ill defined, ii) novel, iii) demanding, iv) complex, and v) exploitable. The definition of a creative strategy or solution varies by the field or job involved, but it can be said that creative behaviours result to some degree in identifying original and better ways to accomplish something useful. Some level of creativity might be expected as a requirement across a wide spectrum of occupations (Shalley and Zhou, 2008; tinyurl.com/clfh925). Examples of organizational-creativity contexts might include business models, strategic decision making, problem solving, product development, managerial activities, marketing, operational processes, financing, and everyday improvements in workplace routines. It should be recognized that there are opportunities to infuse creativity throughout most organizational functions.

\section{Relationship to Innovation}

Creativity is distinguished in the literature from innovation, considered the crafting of creative solutions into new products, processes, or services (Woodman et al., 1993; tinyurl.com/bv7k2qg). Innovation is commonly regarded as the successful implementation of creative ideas and its acceptance by various stakeholders in organizations (Oldham and Cummings, 1996; tinyurl.com/bo9qaje). Creativity is considered a necessary, 


\section{Creativity: Linking Theory and Practice for Entrepreneurs}

Tom Duxbury

but not sufficient pre-condition for innovation (Mumford et al., 2012; tinyurl.com/cx74bfx). The innovation literature often refers to ideation processes as the "fuzzy front end" of innovation, reflecting an unclear understanding of creativity as an initial process step (e.g., Kim and Wilemon, 2002; tinyurl.com/bvpdoqf). Although innovation is often an important end goal of organizational structures supporting creativity, scholars have been careful to maintain separation in the literature of these two constructs (Mumford et al., 2012; tinyurl.com/cx74bfx).

Creativity, as the generation of new ideas that are novel, useful, and appropriate, is therefore the precursor to innovation, the successful commercial exploitation of those ideas. Ideas that do not meet those three criteria at a point in time, from the vantage point of one applying the label, remain as simply ideas. The process of ideation and selection has been conceptually modeled after Darwinian evolutionary theories, in which ideas mutate freely, however only those ideas that are well adapted to the host environment survive. Under Campbell's (1960; tinyurl.com/czs7egz) evolutionary perspective for example, the creative process may be divided into three components: i) variance: the generation of many ideas through brainstorming, flashes of insight or other means; ii) selection: deciding which ideas are pursued as opportunities; and iii) retention: the ability to perpetuate the idea.

These three process stages (VSR: variation, selection, retention) are identifiable inside every organization that turns creative ideas into market innovations. It is important to recognize that threshold-level competency in all three VSR stages is critical to overall ideation performance; the "host environment" needs to be favorable internally. Entrepreneurial organizations are particularly adept at lowering the both the latency and cycle time of ideation, relative to established players. Thus, an organization may generate many ideas but be poor at selecting which ones to implement; alternatively they may demonstrate brilliant operational execution but have little creative capability to initiate the process.

When viewed this way, it becomes more apparent how firms may be creative, but not yet innovative, and this describes the pre-commercialization phase of any new venture. The impact of this difference is more than an academic label: an organization's priorities, activities, and structures must align with the appropriate lifestage objective. In other words: first creativity, then in- novation. It is important that this transition be deliberate, overt, and in the right order. When a startup shifts gears from the exploratory towards the exploitative side of innovation, it is very difficult to support the risk and uncertainty associated with ongoing novel variations (Tushman and O'Reilly, 1996; Calif. Man. Rev. 38: 8-40). Ventures that transition to commercialization phases prematurely risk never establishing the ideation capabilities described earlier.

\section{What is a Creative Person?}

Many perceive individuals as "being creative" or not, citing outstanding examples such as Einstein or Picasso as possessing uniquely creative personalities. "Personalities" refer to a set of personal characteristics that uniquely influence one's cognitions, emotions, motivations, and behaviours in various situations. In summarizing the empirical findings over the previous 15 years, Barron and Harrington (1981; tinyurl.com/bow6bhc) reported a "fairly stable set of core characteristics" linked to creative achievement in many domains. These characteristics included high valuation of esthetic qualities in experience, broad interests, attraction to complexity, high energy, independence of judgment, autonomy, intuition, self-confidence, ability to resolve antinomies, and a firm sense of "being creative".

Many studies have attempted to establish links between creativity and personality attributes, particularly the Five Factor Model (Norman, 1963; tinyurl.com/ce3oqt5). Of the five factors, "openness to experience" is considered the most strongly linked to creativity (e.g., Shalley et al., 2004; tinyurl.com/bpcrpwd). McCrae (1987; tinyurl.com/ccatl6n), for example, tested and found consistent association between divergentthinking-test measures and the openness to experience factor, but not the other four. "Openness" factors include traits of intellectual curiosity, originality, nonconforming, active imagination and aesthetic sensitivity, and preference for variety. Individuals high on the openness-to-experience dimension are considered broad minded, curious, and untraditional (Shalley et al., 2004; tinyurl.com/bpcrpwd).

Besides openness to experience, two other personal attributes have long been linked to creative ability: divergent thinking and cognitive style. Divergent thinking refers to an individual's fluency in generating original or "outside of the box" ideas (Guildford, 1950: tinyurl.com/c3uyztk; Torrance, 1974: tinyurl.com/cbtovpd). Cognitive style describes the way individuals think, per- 


\section{Creativity: Linking Theory and Practice for Entrepreneurs}

Tom Duxbury

ceive, and remember information; it also refers to a person's individual problem-solving and decision-making approaches, which are considered part of creative processes. Kirton's (1976; tinyurl.com/d854ysm) Adaptive-Innovation theory is one of the most popular cognitive style models applied to the investigation of creative problem solving. Kirton (1976; tinyurl.com/d854ysm) contended that everyone may be located on a continuum ranging from an "ability to do things better" (Adapters), to an "ability to do things differently" (Innovators). On one hand, Adaptors are characterized by precision, methodicalness, discipline and conformity; they rarely challenge rules. Innovators, on the other hand, are seen as undisciplined, tangential thinkers who often challenge rules and the status quo to develop new problem solutions (Kirton, 1976; tinyurl.com/d854ysm). In developing measures to evaluate cognitive flexibility, empirical studies have found support for the link between Kirton's Innovator style and creativity (Fleenor and Taylor, 1994; tinyurl.com/d9jd5rr). Although certain traits and cognitions have been linked to creativity in settings that support it, a unique "creativity trait" has never been discovered, however. For entrepreneurs, the right "creative person" for their team might require several means for detection.

\section{Work Contexts and Confluence Theories of Creativity}

In addition to the work environment, Amabile's (1983; tinyurl.com/c7ch702) componential theory of creativity identifies three individual characteristics that must be present for creative output: intrinsic motivation, domain-relevant skills, and creativity-relevant cognitive processes. Of these three, intrinsic motivation - considered to be the individual pursuit of tasks for its own sake - is considered critical to creative performance. Intrinsic motivation, as both a persistent trait and state, creates the drive to persist with difficult tasks, take risks, and overcome obstacles associated with introducing new things. According to Amabile, contextual variables, (e.g., leader support) are thought to affect creativity through their effect on intrinsic motivation. Domain-relevant skills refer to the expertise required to effect meaningful changes to domains, while creativity-relevant cognitive processes include divergent thinking ability, as well as decision-making styles discussed earlier.

Although personal traits may contribute to creative performance, creativity in organizations takes place in a work context, often in groups. The complex interaction of work-setting components serves to enhance or inhib- it the contribution of individual factors; as Woodman, Sawyer, and Griffin (1993; tinyurl.com/bv7k2qg) put it:

"Individual creativity is a function of antecedent conditions (e.g., past reinforcement history, biographical variables), cognitive style and ability (e.g., divergent thinking, ideational fluency), personality factors (e.g., self-esteem, locus of control), relevant knowledge, motivation, social influences (e.g., social facilitation, social rewards), and contextual influences (e.g., physical environment, task and time constraints)."

Sternberg (2006; tinyurl.com/c7rjd9q) emphasized that six distinct but interrelated resources are required, at least at threshold levels, in confluence for creativity: intellectual abilities, knowledge, styles of thinking, personality, motivation, and environment. In considering these factors, both Sternberg (2006; tinyurl.com/c7rjd9q) and Csikszentmihalyi (1999; tinyurl.com/bonozgt) point out that, in the end, creative contributors have options and make deliberate decisions about how their creativity is expressed. In other words, although individual traits are one component of creative output, creative actors themselves will alter or switch their environments to suit their needs. For entrepreneurs establishing a creative context, it is important to recognize three things: i) creative output is contingent upon a supportive work environment; ii) there are several contributing factors, but maintaining intrinsic motivation is key to individual outperformance; and iii) creative actors are decision makers and will not remain in place when the first two criteria are not met.

\section{Putting the Research to Work}

There are three broad contexts in which entrepreneurs interact with creativity: i) structuring a supportive work environment; ii) selecting appropriate team members; and iii) championing ideas externally. Recommendations for these contexts will be discussed in the following sub-sections.

\section{Creative work environment}

Although startup environments are often perceived as being highly creative, in practice the research suggests this is difficult to achieve without deliberate efforts to foster creativity. Entrepreneurs play a critical role in defining values and belief systems that form lasting cultural norms of their organizations. Many of the factors affecting creativity are within the span of control of an entrepreneur-leader in the early-formation stages of an organization, either by vision, goal, and context setting, 


\section{Creativity: Linking Theory and Practice for Entrepreneurs}

Tom Duxbury

or by careful selection of team members. The literature on work contexts that support creativity is extensive and can be distilled into prime factors of leader support for goal setting, autonomy, persistence, open exchange of diverse ideas, and reward systems that encourage experimentation and do not punish failures. The work environment has a well established impact on intrinsic motivation; extrinsic rewards (e.g., performance bonuses, promotions) have not been reliably shown to affect creative output. It is not difficult for organizations to inadvertently discourage creativity over time, particularly as priority shifts to commercialization, rather than ideation. As Steve Jobs has shown, entrepreneurs that embed creativity as a cultural value from the outset will be rewarded with the ability to consistently bring new ideas to market for many years to come.

\section{Selecting team members for creativity}

Forming effective early teams is an important task of entrepreneurs, and the raw materials of creative work are the workers themselves. Although researchers have linked various traits and capabilities to creative potential, the most consistent themes lie in dimensions of openness to new experiences, divergent thinking, intrinsic motivation, and cognitive style. These characteristics are unlikely to be hidden or nascent in adults, and even a simple conversation about past behaviors can be informative. For example, "open" people will likely be able to list new activities they have undertaken recently. Another person may have spent thousands of hours mastering a musical instrument or a project of their own, displaying the personal drive and tenacity associated with intrinsic motivation. In assessing divergent thinking, one established measure simply asks the subject to list as many uses as they can of a household object, such as a brick. Entrepreneurs may also consider using a simple and robust measure of cognitive style, Kirton's Adaption-Innovation Inventory (Kirton, 1976; tinyurl.com/d854ysm). This 32-item, self-reported questionnaire provides an indication of people's preferred approach to problem solving, and high-performing teams will likely benefit from a mix of adaptors and innovators. In work teams, such diversity has long been established as key to generating new approaches and avoiding "group think". The selection of team members or co-founders who hold differing views, and may not fit well with others, is a challenging but essential task for entrepreneurs.

\section{Championing creativity}

An effective entrepreneurial champion is able to gather resources in support of their vision and ideas (e.g., investment capital, team members), whereas a less cap- able one is not. Sternberg (2006; tinyurl.com/c7rjd9q), in his investment theory of creativity, described how entrepreneurs "buy ideas low and sell them high". Sternberg's argument is that virtually all creative ideas start out of favour, due to their required novelty and inherent delays in acceptance by the others in recognizing their usefulness and appropriateness. As new ideas gain acceptance in a field, their commercial value rises, at which point the entrepreneur is celebrated and in a position to "sell their idea high". In this way, entrepreneurs may be said to create new value from ideas.

It has been observed that not all creativity is valued, however. For instance, "creative accounting" commonly has a negative association with novelty, whereas "creative finance" might not. The routine and paradoxical rejection of ideas by those that espouse creativity as goal has interested researchers for some time. When people are motivated to reduce uncertainty, Mueller and colleagues (2012; tinyurl.com/bua5lqa) recently found empirical support for not only an implicit bias against creativity, but an impaired ability to recognize it. This may help entrepreneurs understand why their efforts to sell promising ideas may fail to win over financiers and team members who ought to support them.

In early stages, competencies in championing and promoting ideas are key to acquiring resources needed to turn them into market innovations. It is a myth that good ideas sell themselves, and without effective championing, even the best and most creative ones will inevitably remain in the starting blocks. It is the author's observation that many entrepreneurs have promising ideas, however they struggle in their efforts to champion them and need to be reminded of the consequences of this.

\section{Conclusions}

In this article, the author has provided actionable knowledge for entrepreneurs seeking to make use of creativity research. Creativity matters to entrepreneurs because not only must their initial ideas exhibit dimensions of novelty, usefulness, and appropriateness to justify firm formation, but the capacity to sustainably create commercial value from ideas must be demonstrated. There are many perspectives of creativity resulting from its inherent subjectivity, however this does not detract from the need for understanding how to foster it.

The author has distinguished between creativity as the production of ideas that are novel, useful and appropriate, and innovation: the successful commercialization 


\section{Creativity: Linking Theory and Practice for Entrepreneurs}

Tom Duxbury

of those ideas. Creativity may also be viewed as a judgment made by the field of gatekeepers within domains (i.e., structured knowledge systems that constitute existing knowledge). One test of creativity is to consider whether a lasting change to a domain has been made; the context of initiating change and new value provides a direct link to entrepreneurship.

Three recommendations are provided for entrepreneurs. Firstly, entrepreneurs must ensure their new ventures value and consequently provide deep cultural support for creativity. This requires leaders to create environments that promote the generation, selection, and retention of ideas, while not punishing failed attempts. Secondly, the research provides guidance to entrepreneurs in selecting team members with characteristics linked to creativity (i.e., primarily openness to experience, intrinsic motivation, divergent thinking, and a cognitive style that favours innovation over adaption). Lastly, entrepreneurs are reminded of their critical role in effectively championing ideas, a capability that ensures ideas get what they need to become worthy innovations.

\section{Recommended Reading}

- How to Kill Creativity

(Amabile, 1998; tinyurl.com/2v2yjyd)

- Creativity in Organizations: Facilitators and Inhibitors (Soriano de Alencar, 2012; tinyurl.com/cx74bfx)

- Creativity as an Investment (Sternberg et al., 1997; Calif. Man. Rev. 40(1): 8-20)

\section{About the Author}

Tom Duxbury is Entrepreneur in Residence at Wesley Clover Technologies, a private equity incubator. $\mathrm{He}$ is an advisor to many startups, having co-founded several technology ventures and been awarded a variety of patents. Tom received his engineering degree from the University of Waterloo and an MBA from Queen's University. He is currently completing his PhD in Management at the Sprott School of Business at Carleton University in Ottawa, where he teaches courses in entrepreneurship and innovation.

Citation: Duxbury, T. 2012. Creativity: Linking Theory and Practice for Entrepreneurs. Technology Innovation Management Review. August 2012: 10-15. 